\title{
Value of charcoal media for recovering staphylococci incorporated in Mupirocin ointment
}

\author{
J G BARR, G M HOGG \\ From the Department of Bacteriology, Royal Victoria Hospital, Belfast, Northern Ireland
}

SUMMARY The use of charcoal blood agar supported a good recovery of staphylococci incorporated in Mupirocin ointment in a test in vitro system. The efficacy of this medium was particularly emphasised in the recovery of staphylococci damaged by six hours' exposure to Mupirocin. The media will be of value in following the progress of staphylococcal carriage or infection in patients or carriers being treated with topical Mupirocin.

Many healthy people carry Staphylococcus aureus in their anterior nares, and this source may lead to a more widespread colonisation of the axillae, skin, and perineum. The presence of a reservoir of the potential pathogen may be of particular importance for autoinfection in patients with recurrent skin sepsis, such as infected eczema or recurrent boils, and in immunocompromised patients such as those with leukaemia. The carriage of multiply antibiotic resistant Saureus, including strains resistant to methicillin, can also provide a reservoir of potentially hazardous pathogens which can present serious therapeutic problems.

A new topical agent, Mupirocin, has been shown to have good in vitro activity against $S$ aureus. ${ }^{1} \mathrm{~A}$ controlled trial has shown the value of Mupirocin in eliminating carriage of Saureus, ${ }^{2}$ and the value of nasal applications of Mupirocin ointment in the control of resistant $S$ aureus carriage in a neonatal ${ }^{3}$ and adult ${ }^{4}$ population has been described.

The assessment of the efficacy of Mupirocin in the elimination of carriage is compromised during the period of ointment application by the unavoidable carry over of Mupirocin on swabs from treated sites on to culture plates. Failure to detect staphylococci in these cases could, in some instances, be due to inhibitory concentrations of Mupirocin produced by application of swabs coated in the ointment to solid culture media, and may prevent the detection of viable staphyloccoci.

The present study was carried out to determine if the incorporation of activated charcoal in solid agar culture media or in liquid enrichment media could

Accepted for publication 29 October 1986 enhance the recovery of staphylococci from Mupirocin ointment.

\section{Material and methods}

The reference stains used were $S$ aureus NCTC 6571 and Saureus NCTC 10442 (methicillin resistant). Two clinical isolates of Saureus, resistant to methicillin, MR1 and MR2, were also included. An additional 10 clinical isolates of Saureus and 10 clinical isolates of coagulase negative staphylococci were included in a rapid assessment of charcoal blood agar. The recovery of staphylococci and Mupirocin ointment was confirmed on Columbia agar (GibcoBiocult) supplemented with $5 \%(\mathrm{v} / \mathrm{v})$ horse blood alone or supplemented with $5 \%(\mathrm{v} / \mathrm{v})$ horse blood and $2 \%(w / v)$ activated charcoal (Sigma Chemical).

Enrichment culture was carried out in brain heart infusion broth (BHI) (Gibco Biocult) and in BHI broth supplemented with $2 \%(\mathrm{w} / \mathrm{v})$ activated charcoal.

The inocula for Mupirocin recovery experiments were prepared by overnight incubation of staphylococci in BHI broth. Sequential 10-fold dilutions of this inoculum were prepared in the same medium. Mueller-Hinton agar (Oxoid CM 40S) was used for determining minimum inhibitory concentrations of Mupirocin.

\section{ENUMERATION OF BACTERIA}

Dilutions of bacterial suspensions were prepared in quarter strength Ringer's solution and the numbers of colony forming units per $\mathrm{ml}(\mathrm{cfu} / \mathrm{ml})$ were determined using the spread plate method on Columbia agar enriched with $5 \%(\mathrm{v} / \mathrm{v})$ horse blood. Plates were incubated for 48 hours at $37^{\circ} \mathrm{C}$. 
OINTMENT

Mupirocin ointment was provided by Beecham's Laboratories, Worthing. The ointment contained 2\% $(w / v)$ Mupirocin in a paraffin base.

\section{ANTIBIOTIC SUSCEPTIBILITY TESTING}

Minimum inhibitory concentrations (MIC) were carried out using the agar incorporation method. Four hour cultures in BHI broth were used as inocula and dispensed using a multipoint inoculator (Denley Instruments Ltd) on to Mueller-Hinton agar plates containing two-fold serial dilutions of Mupirocin.

\section{VELVET PAD TRANSFER}

In cases where swabs coated in the ointment yielded no growth after initial plating on blood agar or charcoal blood agar, sterile velvet pads were used to transfer from the surface of each plate on to fresh plates of both blood agar and charcoal blood agar. The presence of growth on these plates was recorded after 48 hours' incubation at $37^{\circ} \mathrm{C}$.

\section{PREPARATION OF THE TEST SYSTEM}

Templates of squares $(2 \mathrm{~cm} \times 2 \mathrm{~cm})$ were marked out on the base of antibiotic assay plates (Luckham Ltd) using non-water soluble markers. The plates were sterilised by autoclaving with lids in place.

Aliquots of ointment $(0.9 \mathrm{~g})$ were weighed out aseptically into sterile bijou bottles and $0.1 \mathrm{ml}$ volume of an inoculum dilution of staphylococci in BHI broth was added. An emulsion of the inoculum broth and paraffin based ointment was obtained by mechanical blending with a sterile glass rod.

The inoculated ointment was loaded on to the sterile surface of the assay plate using a sterile swab and the ointment evenly spread over the plate using the long edge of a sterile glass microscope slide.

Using this method $1 \mathrm{~g}$ of emulsion could be spread over an area equivalent to thirty $2 \mathrm{~cm} \times 2 \mathrm{~cm}$ squares. The number of bacteria applied to each $4 \mathrm{~cm}^{2}$ square could thus be quantitated.

\section{SAMPLING OF THE TEST SYSTEM}

The numbering of squares on the assay plate was randomised and at each sampling time six replicate squares were swabbed for each treatment. The ointment was removed from each square individually with a serum coated swab (Medical Wire and Equipment Co Ltd) and plated out on blood agar or blood agar plus charcoal.

To investigate the value of enrichment culture replicate swabs of squares were broken into BHI broth or BHI broth plus charcoal. After 24 hours' incubation at $37^{\circ} \mathrm{C} 100 \mathrm{ul}$ volumes broth were subcultured on to blood agar and blood agar plus charcoal.

Assay plates were sampled either immediately after application of the ointment ( 0 hours' incubation) or after incubation for six hours at $37^{\circ} \mathrm{C}$.

\section{RECORDING OF RESULTS}

Growth of staphylococci on all culture plates was recorded semiquantitatively after 24 and 48 hours' incubation at $37^{\circ} \mathrm{C}$-that is, $+++=$ (confluent growth), $++=10-100$ colonies, $+=1-10$ colonies, and $-=$ no growth detected.

RAPID SCREENING METHOD FOR THE COMPARISON OF BLOOD AND CHARCOAL BLOOD AGAR

Inoculum suspensions of 10 strains of $S$ aureus and 10 strains of coagulase negative staphylococci were prepared in BHI broth and diluted in BHI broth to give inoculum suspensions of about $10^{7} \mathrm{cfu} / \mathrm{ml}$ for each organism; $0.05 \mathrm{ml}$ of inoculum was added to $0.5 \mathrm{~g}$ sterile Mupirocin ointment, emulsified, and spread over $152 \mathrm{~cm} \times 2 \mathrm{~cm}$ squares on the template, as described above. Squares $\left(4 \mathrm{~cm}^{2}\right)$ were sampled immediately and after six hours' incubation and plated on both blood agar and charcoal blood agar. A semiquantitative assessment of growth was made as described above.

\section{Results}

The minimum inhibitory concentration of Mupirocin for all staphylococci examined was between 0.12 and $0.5 \mathrm{mg} / \mathrm{l}$.

\section{REPRODUCIBILITY OF THE METHOD}

A high degree of reproducibility was found in growth derived from replicate swabs of random $4 \mathrm{~cm}^{2}$ areas plated on both blood agar and charcoal blood agar. For each treatment at least five of six replicate platings yielded the same semiquantitative growth. These results gave confidence in the value of the rapid screening method described for the examination of larger numbers of strains.

\section{RECOVERY AFTER MINIMAL EXPOSURE TO} MUPIROCIN

With all strains examined by the test method, the recovery of staphylococci was enhanced on charcoal blood agar. The increased recovery on charcoal blood agar was most pronounced with the lower inoculum concentrations (table 1). With three of four strains, recovery using the lowest inoculum concentration $\left(10^{2} \mathrm{cfu} / 4 \mathrm{~cm}^{2}\right.$ surface area) was obtained only on charcoal blood agar.

\section{RECOVERY AFTER SIX HOURS' EXPOSURE TO} MUPIROCIN

Recovery of all strains at all inoculum concentrations studied was enchanced on charcoal blood agar. In the 
Table 1 Effect of inoculum concentration, recovery medium, and time of exposure to Mupirocin on recovery of staphylococci from Mupirocin ointment

\begin{tabular}{|c|c|c|c|c|c|}
\hline \multirow[b]{3}{*}{ Organism } & \multirow{3}{*}{$\begin{array}{l}\text { Inoculum } \\
\left(c f u / 4 \mathrm{~cm}^{2}\right)\end{array}$} & \multicolumn{2}{|c|}{ Recovery on blood agar } & \multicolumn{2}{|c|}{ Recovery on blood charcoal agar } \\
\hline & & \multicolumn{4}{|c|}{ Incubation with Mupirocon ointment (hours) } \\
\hline & & $\overline{0}$ & 6 & 0 & 6 \\
\hline$S$ aureus (NCTC 10442) & $\begin{array}{l}10^{6} \\
10^{4} \\
10^{2}\end{array}$ & $\begin{array}{l}+ \\
+ \\
-\end{array}$ & $\begin{array}{l}+ \\
- \\
-\end{array}$ & $\begin{array}{l}+++ \\
+ \\
-\end{array}$ & $\begin{array}{l}+t \\
+ \\
-\end{array}$ \\
\hline$S$ aureus (NCTC 6571) & $\begin{array}{l}10^{6} \\
10^{4} \\
10^{2}\end{array}$ & $\begin{array}{l}++ \\
-\end{array}$ & $\begin{array}{l}+ \\
-\end{array}$ & $\begin{array}{l}+++ \\
++ \\
+\end{array}$ & $\begin{array}{l}++t \\
+t \\
+\end{array}$ \\
\hline$S$ aureus $(\mathrm{MR} / 1)$ & $\begin{array}{l}10^{6} \\
10^{4} \\
10^{2}\end{array}$ & $\begin{array}{l}++t \\
++ \\
+\end{array}$ & $\begin{array}{l}+ \\
+ \\
-\end{array}$ & $\begin{array}{l}+++ \\
+++ \\
+\end{array}$ & $\begin{array}{l}+t+ \\
+t \\
t\end{array}$ \\
\hline$S$ aureus $(\mathrm{MR} / 2)$ & $\begin{array}{l}10^{6} \\
10^{4} \\
10^{2}\end{array}$ & $\begin{array}{l}++ \\
+ \\
-\end{array}$ & $\begin{array}{l}+ \\
-\end{array}$ & $\begin{array}{l}++t \\
++ \\
+\end{array}$ & $\begin{array}{l}+t+ \\
t+ \\
t\end{array}$ \\
\hline
\end{tabular}

Recovery was recorded semiquantitatively as +++ , confluent growth;,$++ 10-100$ colonies;,$+ 1-10$ colonies; and - , no growth.

absence of charcoal three of four strains were detected only at the highest inoculum concentration $\left(10^{6}\right.$ $\mathrm{cfu} / 4 \mathrm{~cm}^{2}$ ). In contrast, with charcoal media three of four strains were detected at the lowest inoculum concentration $\left(10^{2} \mathrm{cfu} / 4 \mathrm{~cm}^{2}\right)$.

\section{EFFECT OF TIME OF EXPOSURE TO MUPIROCIN ON RECOVERY ON SOLID MEDIA}

For all four test strains, the extended exposure to Mupirocin resulted in a reduced recovery of staphylococci on blood agar. In contrast, with the use of charcoal blood agar, very little difference in recovery was noted between minimal exposure ( 0 hours) and six hours' incubation in the presence of Mupirocin (table 1).

\section{RECOVERY OF STAPHYLOCOCCI ON SOLID}

MEDIA AFTER 24 HOURS' INCUBATION OF

SWABS IN BROTH CULTURE

When swabs were incubated for 24 hours at $37^{\circ} \mathrm{C}$ in BHI broth before plating on solid media, recovery of viable bacteria was obtained only with the highest initial inoculum (about $10^{6} \mathrm{cfu} / 4 \mathrm{~cm}^{2}$ ). Using BHI broth plus charcoal, bacteria were recovered with initial inocula of about $10^{6} \mathrm{cfu} / 4 \mathrm{~cm}^{2}$ and $10^{4} \mathrm{cfu} / 4 \mathrm{~cm}^{2}$.

All strains showed the same pattern of recovery after incubation in either BHI broth alone or supplemented with charcoal. With both broth cultures, no difference was noted in the recovery of colony forming bacteria from inocula incubated in Mupirocin ointment for the minimal period ( 0 hours) or for six hours. Subcultures from both broth cultures did not yield any difference between viable count on plating on blood agar or charcoal blood agar.

Allowing for the initial inoculum dilution induced by suspending swabs in broth culture, the recovery of viable colony forming units from broth culture was less efficient than direct plating of swabs on solid charcoal blood agar.

Table 2 gives a comparison of blood agar and char-

Table 2 Semiquantitive assessment of recovery of $S$ aureus and coagulase negative staphylococci from Mupirocin ointment on blood and charcoal blood agar

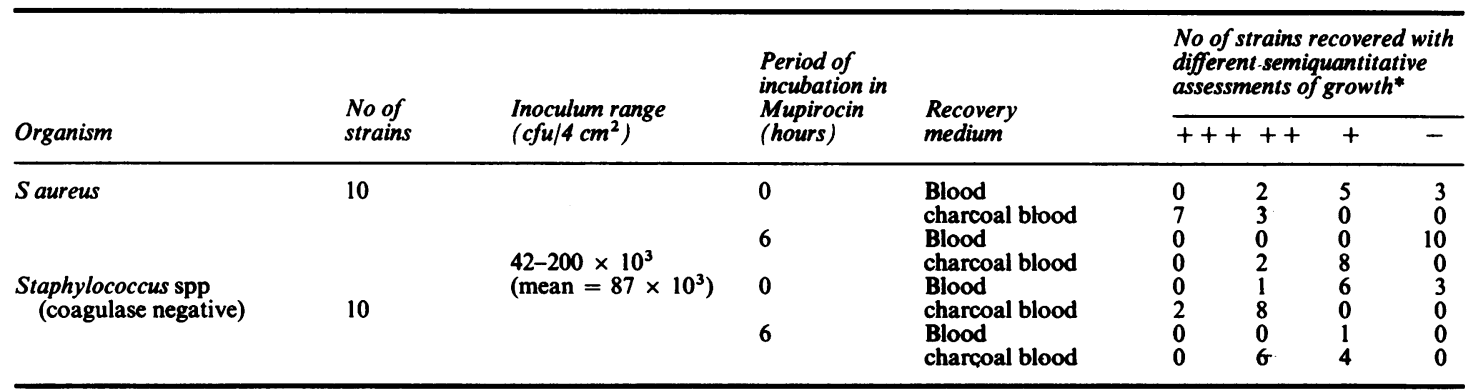

* Recovery was recorded semiquantitatively as +++ , confluent growth;,$++ 10-100$ colonies;,$+ 1-10$ colonies; and - , no growth. 
coal blood agar in the recovery of 20 staphylococci from Mupirocin ointment. With both Saureus and coagulase negative staphylococci, a greater recovery of bacteria was obtained on charcoal blood agar; the difference between media was especially emphasised when staphylococci were exposed to Mupirocin for six hours. When bacteria had been exposed to Mupirocin for six hours, colonies were often small after 24 hours' incubation on both blood and charcoal blood agar; accordingly, colony counts were made after 48 hours' incubation. With four strains of coagulase negative staphylococci, growth was not recorded after 48 hours' incubation on blood agar, but the presence of small numbers of viable cells could be shown by velvet pad transfer on to blood agar or charcoal blood agar plates. With all four bacteria, initial plating on charcoal blood agar had yielded positive growth.

\section{Discussion}

$S$ aureus nasal carriage is notoriously difficult to eliminate. Antibiotics such as gentamicin ${ }^{5}$ and rifampicin, ${ }^{6}$ which have an established place in the treatment of overt infections, can, with some success, be used to eliminate nasal carriage by topical or systemic treatment, but the potential selection of resistance means that this approach is now out of favour. The use of Mupirocin, which has no claims as a systemic agent, is therefore attractive, and this is reinforced by the rare or non-existence of naturally occurring resistant $S$ aureus and by the apparent nonselection of resistant strains during and after nasal treatment with Mupirocin. ${ }^{2}$

The value of Mupirocin in the elimination of nasal carriage has been assessed and found to be successful by Casewell, ${ }^{2}$ who also showed that during the period after treatment only a small percentage of those treated showed a relapse of colonisation with the pretreatment strain.

Although workers have found that persistent carriage can be quickly eliminated in most patients in two days, this may not be so with all patients or micro-organisms, and an assessment of the progress of treatment is of prime importance, especially in an epidemic situation.

The use of specific and non-specific antibiotic inactivating methods has already found a place in clinical bacteriology in the field of blood cultures, where the addition of specific enzymes such as B-lactamases or non-specific additives, such as antibiotic removing resins, ${ }^{7}$ has been successful in reducing antibiotic concentrations in blood culture media. The use of charcoal has been investigated here as a non-specific measure for the inactivation of Mupirocin in solid and liquid media.
We have shown that with the use of blood agar alone as a recovery medium many staphylococci could not be detected (tables 1 and 2). Thus detection failure was especially high when the staphylococci were damaged by exposure to Mupirocin for a considerable time. The use of charcoal agar ensured the recovery of all staphylococci examined by the rapid screening method (table 2), even under conditions of extended exposure to Mupirocin. The results shown in table 1 indicate that the inclusion of charcoal in the medium could increase the sensitivity of detection of staphylococci by 10000 -fold.

It is likely that charcoal binds Mupirocin nonspecificity and permits growth of the staphylococci. Certainly on blood agar alone, Mupirocin carried over on a swab continues to have an inhibitory effect; with some strains of staphylococci examined, however, the survival of viable cells on blood agar for 48 hours in the presence of Mupirocin could be shown by velvet pad transfer to fresh blood agar media.

The value of a charcoal enriched BHI media could not be shown. The concentration of Mupirocin in charcoal broth remained inhibitory, and the prolonged exposure of staphylococci to Mupirocin may have reduced the efficiency of recovery. The lower concentration of Mupirocin resulting from dilution in broth seemed to negate the efficiency of elimination of staphylococci. With Mupirocin ointment, treatment is likely to vary with both the organism and the patient. Certainly, where colonisation or infection with multiply resistant (including methicillin resistant) staphylococci provide reservoirs for epidemic spread, Mupirocin could play an important part in containment along with other established procedures. $^{7-9}$ In such cases confidence in the efficacy of Mupirocin in the elimination of the potentially epidemic staphylococci should be obtained by using the most sensitive culture methods available. Charcoal agar increases the sensitivity of detection of staphylococci in ointment and should be used to follow the progress of elimination of staphylococci during treatment and immediately after treatment when residual Mupirocin is present.

\section{References}

1 Casewell MW, Hill RLR. In-vitro activity of mupirocin (pseudomonic acid) against clinical isolates of Staphylococcus aureus. Antimicrob Agents Chemother 1985;15:523-31.

2 Casewell MW, Hill RLR. Elimination of nasal carriage of Staphylococcus aureus with Mupirocin (pseudomonic acid)-A controlled trial. $J$ Antimicrob Chemother 1986;17:365-72.

3 Davies EA, Emmerson AM, Hogg GM, Patterson MF, Shields MD. An outbreak of infection with a gentamicin and methicillin resistant Staphylococcus aureus in a special care baby unit: value of topical mupirocin. $J$ Hosp Infect (in press).

4 Dacre JE, Emmerson AM, Jenner EA. Nasal carriage of gen- 
tamicin and methicillin resistant Staphylococcus aureus treated with topical pseudomonic acid. Lancet 1983;ii:1036.

5 Sande MA, Mandell GL. Effect of Rifampicin on nasal carriage of Staphylococcus aureus. Antimicrob Agents Chemother 1975;7:294-7.

6 Wheat LJ, Kohler AB, White A. Treatment of nasal carriers of coagulase positive Staphylococci. In: Maibach HI, Aly R, eds. Skin microbiology: relevance to clinical infection. New York: Springer-Verlag. 1981:50-8.

7 Appleman MD, Swinney RS, Heseltine PNR. Evaluation of the antibiotic removal device. J Clin Microbiol 1982;15:278-81.

8 Hospital Infection Society and British Society for Antimicrobial
Chemotherapy (1986). Guidelines for the control of epidemic methicillin-resistant Staphylococcus aureus. J Hosp Infect 1986;7:193-201.

9 Selkon JB, Stokes ER, Ingham HR. The role of an isolation unit in the control of hospital infection with methicillin resistant staphylococci. J Hosp Infect 1980;1:41-6.

Requests for reprints to: Dr JG Barr, Department of Bacteriology, Royal Victoria Hospital, Grosvenor Road, Belfast BT12 6BA, Northern Ireland. 